\title{
Fatigue, Exercise Tendency and Physical Activity Behavior of Female Patients with Breast Cancer
}

\author{
Sabriye Ercan ${ }^{1 *}$, Ahsen Oğul ${ }^{2}$, Murat Koçer ${ }^{3}$, Esma Arslan¹, Ferdi Başkurt ${ }^{4}$, \\ Cem Çetin ${ }^{1}$
}

\begin{abstract}
${ }^{1}$ Süleyman Demirel University, Faculty of Medicine, Department of Sports Medicine, Isparta, Turkey.

${ }^{2}$ Diyarbakır Gazi Yaşargil Education and Research Hospital, Department of Sports Medicine Department, Diyarbakır, Turkey.

${ }^{3}$ Antalya Education and Research Hospital, Department of Oncology, Antalya, Turkey.

${ }^{4}$ Süleyman Demirel University, Faculty of Health Sciences, Department of Physiotherapy and Rehabilitation, Isparta, Turkey.
\end{abstract}

\begin{abstract}
The aim of this study was to compare the level of fatigue and physical activity attitudes between breast cancer patients and healthy individuals. The study included female patients diagnosed with breast cancer $\left(\right.$ Group $\left._{C a}\right)$ and healthy women (Group Control). In the questionnaire form prepared by the researchers; sociodemographic characteristics of the participants, information such as smoking and comorbid diseases were questioned. In patients diagnosed with breast cancer, information on the diagnosis of breast cancer had been detailed. "International Physical Activity Questionnaire-short form", "Exercise Stages of Change Questionnaire " and "Brief Fatigue Inventory" were applied to all participants. The study included 57 women (age: $51.7 \pm 9.1$ years) diagnosed with breast cancer and 58 healthy (age: $52.7 \pm 10.4$ years) women not diagnosed with cancer $(p=0.58)$. No difference was found between the participants' sociodemographic characteristics excluding education $(p>0.05)$. The difference between the education levels of the groups was determined at the level of

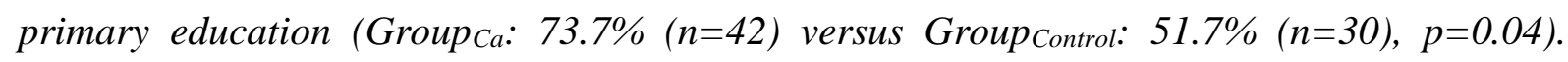
There was no difference between the groups in terms of physical activity levels (Group Ca:

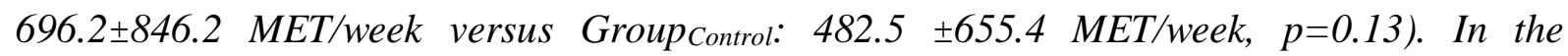
exercise stages of change questionnaire, it was determined that women diagnosed with breast cancer were found to be more in the 'precontemplation' and 'preparation' stages than women in the control group $(p=0.004)$. Women in the breast cancer group stated that they felt fatigue/weakness that made a significant difference with the control group $(p=0.001)$. However, according to the Brief Fatigue Inventory, it was observed that the effects of fatigue, severity and fatigue on daily life did not make any difference between the groups $(p>0.05)$. In
\end{abstract}

\footnotetext{
* Corresponding author: Sabriye Ercan, Medical Faculty of Süleyman Demirel University, Department of
} Sports Medicine. E-mail: sabriveercan@ @mail.com. ORCID ID: 0000-0001-9500-698X. 
this study, no difference was found between the activity level and fatigue level in breast cancer patients compared to healthy individuals. When the physical activity behaviours were evaluated, it was determined that the breast cancer group had more precontemplation and preparation in exercise stages.

Keywords: Breast Cancer, Physical activity, Fatigue, Exercise behaviour.

\section{Introduction}

Cancer is one of the most important health problems threatening public health worldwide. Worldwide, approximately 25$30 \%$ of all cancers in women originate from the breast (1). Breast cancer is on the top among the ten most common cancers in women in our country and the age of breast cancer in women is gradually decreasing (2). According to the data of 2016 Turkish Statistical Institute, standardized incidence rate by age of breast cancer in women was 45.6/100.000 (3).

It is known that factors such as age, obesity, insufficient physical activity, alcohol consumption of 2 or more measures per day, nulliparity, history of first birth over 35 years old, early menarche, late menopause, genetic mutations such as BRCA-1, BRCA-2, atypical ductal hyperplasia, atypical lobular hyperplasia and a family history of breast cancer increase the risk of breast cancer (4). Being able to intervene in the factors that are listed among the risk factors and can be modified is important as it provides primary protection (5). Increasing the level of physical activity, which is among the modifiable risk factors; in addition to primary prevention, it is also effective in the treatment of cancer-related fatigue, which is the most frequently reported symptom in women with breast cancer (6).

In a study by Backman et al., women who received chemotherapy were asked to walk
10000 steps every day for 10 weeks, and it was reported that edema, pain and fatigue decreased with increased mobility in this process. In addition, it had been pointed out that physical activity can preserve arm and shoulder mobility and reduce lymphedema in women diagnosed with breast cancer (7). In a meta-analysis by Lipsett et al., the effects of an exercise program applied as a part of the treatment during adjuvant radiotherapy in breast cancer were examined, and it was shown that performing aerobic exercise and resistance exercises under supervision had positive effects on reducing cancer-related fatigue and increasing the quality of life (6).

Although fatigue is a common symptom that negatively affects the quality of life of cancer patients, little is known about its mechanisms (8). This situation has been tried to be explained by many factors such as changes in cytokine release, anaemia, nutritional and sleep disorders, hormonal changes, treatment side effects, psychosocial factors, and decreased physical activity (9). On the other hand, cancer and oncological treatments cause impairment in energy metabolism, resulting in fatigue and a decrease in physical performance. In addition to changes in energy metabolism, physical activity decreases and fatigue becomes more severe due to many reasons such as the cause of myopathy by some therapeutic agents, cancer and treatment-related 
cytokine changes, nutritional deficiencies and rest cure (9). Increasing participation in physical activity is important in reversing all these negative factors (5).

Considering these mechanisms, our hypothesis; the difference between fatigue level, participation in physical activity and physical activity behaviours will be observed in individuals diagnosed with breast cancer compared to healthy individuals. The aim of this study is to compare the level of participation in physical activity, physical activity behaviour and fatigue of individuals diagnosed with breast cancer and healthy individuals.

\section{Materials and methods}

The study was approved by the decision of the local ethics committee dated June 25, 2019 and numbered 196. Before starting the research, it was calculated that the sample size in the groups should be 55 when the confidence level was accepted as $80 \%$ and the precision rate was 0.05 in the power analysis performed with the $\mathrm{G}^{*}$ power program.

The study included female patients older than 18 years with a diagnosis of breast cancer (Group Ca) and healthy women without cancer diagnosis (Group Control). People who could not be contacted at a level that could give reliable answers to the questionnaires were excluded from the study.

In the questionnaire form prepared by the researchers; information such as age, body mass index, educational and marital status, place of residence, smoking and comorbid diseases were questioned. Information on the diagnosis of breast cancer was detailed for the patients in Group ca. After the sociodemographic and medical history information were evaluated, the $\begin{array}{lcr}\text { participants } & \text { were } & \text { administered } \\ \text { 'International } & \text { Physical } & \text { Activity }\end{array}$ Questionnaire (IPAQ)-short form', 'The Exercise Stages of Change Questionnaire (ESCQ)' and 'Brief Fatigue Inventory (BFI)'.

The questionnaire was asked to be filled in face to face by the participants. While filling out the questionnaires, the participants who wanted to ask any questions were allowed to ask questions and the questions of the participants were answered by the physician applying the questionnaire.

\section{The questionnaires}

\section{International Physical Activity} Questionnaire-short form

In order to evaluate the physical activity levels of the participants, IPAQ-short form, whose validity and reliability in Turkish was provided, was used (10). Based on the answers to the questionnaire, the total score was calculated as MET/week. In this survey; physical activity level below 600 MET-min/week is considered as sedentarylow physically active individual, 600-3000 MET-min/week as active individual, and over 3000 MET-min/week as highly physically active individual (11).

Exercise Stages of Change Questionnaire ESCQ, which was developed according to the transtheoretic model and whose validity and reliability in Turkish was ensured, was used to determine the exercise behaviour level of the participants. This scale consists of 4 questions that can be answered 'yes' or 'no'. According to the answers given by the participants; they were in one of the steps of 'Precontemplation (1st and 2nd questions $=\mathrm{No})$, Contemplation $(1 \mathrm{st}$ question $=$ No, 2nd question = Yes), Preparation (1st question $=$ Yes, 3rd question $=$ No), Action (1st and 3rd 
question=Yes, question $4=\mathrm{No}$ ) or Maintenance (1st, 3rd and 4th questions=Yes)' (12).

\section{Brief Fatigue Inventory}

BFI with 10 questions of validity and reliability in Turkish was used to determine the severity of fatigue of the participants and the effects of fatigue on daily life (13). The first question of the scale was designed to answer the unusual feeling of fatigue or weakness in the last week with the answer 'yes' or 'no'. A score between 0-10 points can be given to each of the other 9 questions in the scale, and a higher score indicates increased fatigue. In the scale, the severity of fatigue is evaluated with 3 questions (questions 1, 2 and 3) and the effects of fatigue on daily life with 6 questions (questions $4 \mathrm{a}, 4 \mathrm{~b}, 4 \mathrm{c}$, $4 \mathrm{~d}, 4 \mathrm{e}$ and $4 \mathrm{f}$ ). The Total BFI score is calculated by summing the scores given to all questions, the Fatigue Severity Score to the first 3 questions, and the Fatigue Interference Score to the other 6 questions (14). The Global BFI score is determined by the average of the scores given to 9 questions (15) and if this score is ' 0 ' is not fatigue, '1-3 points' is low fatigue, '4-6 points' is moderate fatigue, ' 7 points and above' is interpreted as a severe level of fatigue (16).

\section{Statistical Analysis}

SPSS v23 package program was used in the analysis of the data. Participants' data were evaluated using descriptive statistical methods. Whether there was a difference between the groups was examined by chisquare test and $t$ test in independent groups. $\mathrm{P}$ value was accepted as significant at the 0.05 level. Data were presented as n, $\%$ and mean \pm standard deviation.

\section{Results}

The age of female patients $(n=57)$ with breast cancer who participated in the study was $51.7 \pm 9.1$ years; the age of healthy women $(\mathrm{n}=58)$ who were not diagnosed with breast cancer was $52.7 \pm 10.4$ years $(\mathrm{p}$ $=0.58)$. There is no difference $(p=0.87)$ in terms of body mass index values of the groups (Group ca: $28.8 \pm 5.3 \mathrm{~kg} / \mathrm{m} 2$ versus Group Control: $28.6 \pm 5.1 \mathrm{~kg} / \mathrm{m} 2$ ) .

While $73.7 \%(n=42)$ of the women in Group $\mathrm{Ca}$ had primary school education, $12.3 \%(\mathrm{n}=7)$ had a high school education, $14 \%(n=8)$ had a university education, women in Group control had completed their education at $51.7 \%(\mathrm{n}=30)$ primary school, $25.9 \%(\mathrm{n}=15)$ high school, $22.4 \%$ ( $\mathrm{n}=13$ ) university level, respectively. The difference between the education levels of the groups was determined at the primary education level $(\mathrm{p}=0.04)$.

There is no difference between place of residence, employment status, marital status, presence of comorbid diseases, regular medication use and smoking of the participants. ( $p>0.05)$, (Table 1).

Of the women in Group ca 3.5\% (n=2) had a newly diagnosed but not yet started treatment, $31.6 \%(\mathrm{n}=18)$ were in the treatment phase and $64.9 \%(n=37)$ were in remission. The time since these patients were diagnosed with breast cancer was $52.5 \pm 43.9$ months. The most common diagnosis of breast cancer was detected in stage 2 (Figure 1). The patients mostly received combined therapy consisting of surgery, chemotherapy and radiotherapy (Table 2).

According to their response to the IPAQ, the physical activity level of women in Group Ca was $696.2 \pm 846.2$ MET/week, the score for women in Group control was calculated as $482.5 \pm 655.4 \mathrm{MET} /$ week $(\mathrm{p}$ $=0.13$ ). It was determined that the change of exercise stages of women diagnosed with breast cancer made a difference with 
Group control in the "Precontemplation" and "Preparation" levels $(\mathrm{p}=0.004)$, (Table 3).

Table 1: Characteristics of Participation, $\mathrm{n}=$ number of patients, $\mathrm{SD}=$ standard deviation.

\begin{tabular}{|c|c|c|c|}
\hline Characteristics & $\operatorname{Group}_{\mathrm{Ca}}(\mathrm{n}=57)$ & Group Control $(n=58)$ & p value \\
\hline Place of residence, $\%(\mathrm{n})$ & & & 0.44 \\
\hline Village & $5.3(3)$ & $10.3(6)$ & \\
\hline District & $28.1(16)$ & $20.7(12)$ & \\
\hline City center & $66.7(38)$ & $69(40)$ & \\
\hline Employment status, \% (n) & & & 0.2 \\
\hline Employed full time & $21.1(12)$ & $10.39(6)$ & \\
\hline Housewife & $77.1(44)$ & $77.5(45)$ & \\
\hline Retired & $1.8(1)$ & $12.1(7)$ & \\
\hline Marital status, \% (n) & & & 0.07 \\
\hline Unmarried (single, widoved) & $22.8(13)$ & $10.3(6)$ & \\
\hline Married & $77.2(44)$ & $89.7(52)$ & \\
\hline Comorbidities, \% (n) & & & 1 \\
\hline Yes & $42.1(24)$ & $43.1(25)$ & \\
\hline No & $57.9(33)$ & $56.9(33)$ & \\
\hline Regular medication use, \% (n) & & & 0.99 \\
\hline Yes & $1.8(1)$ & $0(0)$ & \\
\hline No & $98.2(56)$ & $100(58)$ & \\
\hline Smokers, \% (n) & & & 0.82 \\
\hline Yes & $7(4)$ & $13.8(8)$ & \\
\hline Give up smoking & $22.8(13)$ & $12.1(7)$ & \\
\hline No & $70.2(40)$ & $74.1(43)$ & \\
\hline
\end{tabular}

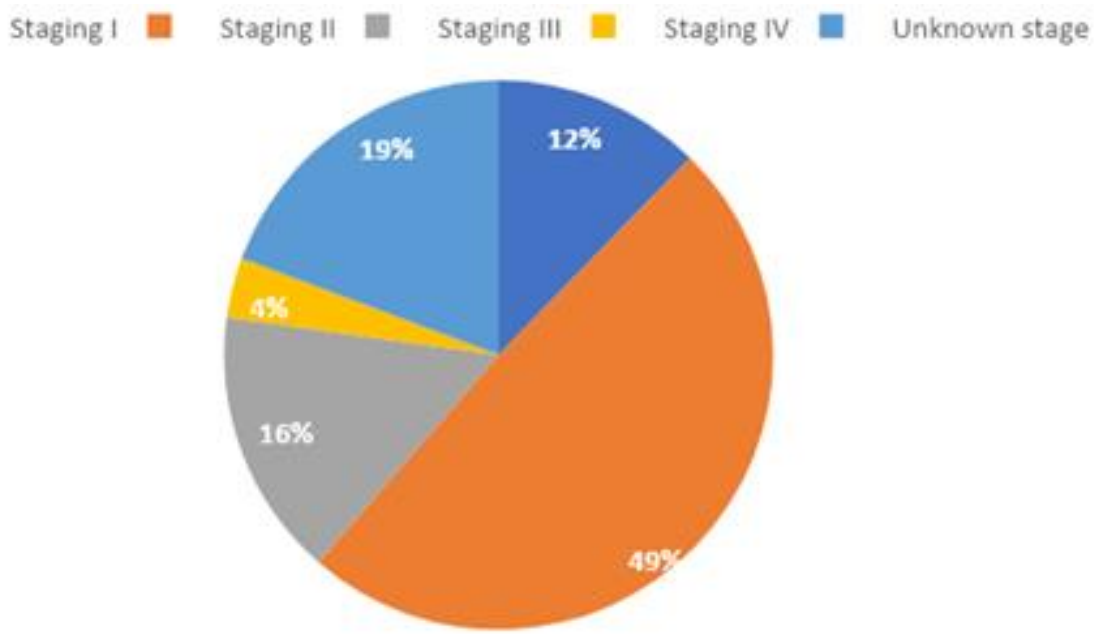

Figure 1: Cancer staging.

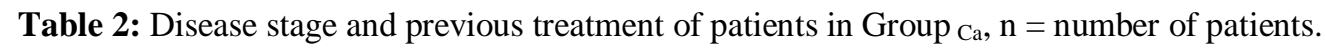

\begin{tabular}{ll}
\hline Previous treatment & \% (n) \\
\hline Chemotherapy & $1.8(1)$ \\
Surgery and Chemotherapy & $26.3(15)$ \\
Surgery and Radiotherapy & $3.5(2)$ \\
Chemotherapy and Radiotherapy & $7(4)$ \\
Surgery, Chemotherapy and Radiotherapy & $61.4(35)$ \\
\hline
\end{tabular}


Table 3: Distribution of the Exercise Stages of Change Questionnaire, $n=$ number of patients, $S D=$ standard deviation. *: There is a significant difference of 0.05 between the groups marked with the letters a and $\mathrm{b}$.

\begin{tabular}{llll}
\hline Classification, \% (n) & Group $_{\mathbf{c a}}(\mathbf{n}=\mathbf{5 7})$ & Group Control $^{(\mathbf{n}=\mathbf{5 8})}$ & p value \\
\hline Precontemplation & $29.8(17)^{\mathbf{a}}$ & $6.9(4)^{\mathbf{b}}$ & $0.004 *$ \\
Contemplation & $7(4)$ & $15.5(9)$ & \\
Preparation & $17.5(10)^{\mathbf{a}}$ & $3.4(2)^{\mathbf{b}}$ & \\
Action & $21.1(12)$ & $32.8(19)$ & \\
Maintenance & $24.6(14)$ & $41.4(24)$ & \\
\hline
\end{tabular}

When the participants' presence of fatigue was questioned; women in Group ca stated that they felt unusual fatigue or weakness in the last week, which would make a significant difference with Group control $(\mathrm{p}$
$=0.001)$. On the other hand, according to the BFI, it was observed that fatigue, its severity and its effects on daily life did not make a difference between the groups ( $>0.05)$, (Table 4-5).

Table 4: Distribution of Fatigue Classification According to the BFI, $n=$ number of patients, $S D=$ standard deviation, BFI: Brief Fatigue Inventory. *: There is a significant difference of 0.05 between the groups marked with the letters $a$ and $b$.

\begin{tabular}{llll}
\hline & Group Ca $(\mathbf{n}=\mathbf{5 7})$ & Group Control $(\mathbf{n}=\mathbf{5 8})$ & p value \\
\hline Feeling unusual fatigue, \% (n) & & & \\
$\quad$ Yes & $35.1(20)^{\mathbf{a}}$ & $8.6(5)$ & $0.001 *$ \\
$\quad$ (b & $91.4(53)$ & \\
No & $64.9(37)^{\mathbf{a}}$ & & \\
Classification, \% (n) & & $12.1(7)$ & 0.09 \\
$\quad$ Absent fatigue & $22.8(13)$ & $44.8(26)$ & \\
Mild fatigue & $24.6(14)$ & $37.9(22)$ & \\
$\quad$ Moderate fatigue & $42.1(24)$ & $5.2(3)$ & \\
Severe fatigue & $10.5(6)$ & & \\
\hline
\end{tabular}

Table 5: Brief Fatigue Inventory Scores

\begin{tabular}{llll}
\hline & Group Ca $(\mathbf{n}=\mathbf{5 7})$ & Group Control $(\mathbf{n}=\mathbf{5 8})$ & p value \\
\hline Total Brief Fatigue Inventory score & $33.4 \pm 24.2$ & $32.5 \pm 21.1$ & 0.82 \\
Fatigue severity score & $11.5 \pm 8.5$ & $13.3 \pm 7.3$ & 0.22 \\
$\quad$ Now fatigue & $3.7 \pm 2.9$ & $4.4 \pm 2.6$ & 0.18 \\
$\quad$ Usual fatigue & $3.8 \pm 2.9$ & $4.2 \pm 2.5$ & 0.35 \\
$\quad$ Worst fatigue & $4 \pm 3$ & $4.7 \pm 2.6$ & 0.22 \\
Fatigue Interference score & $21.9 \pm 16.8$ & $19.2 \pm 14.7$ & 0.35 \\
$\quad$ General activity & $3.5 \pm 3$ & $3.5 \pm 2.8$ & 0.99 \\
Mood & $4 \pm 3.3$ & $3.9 \pm 3$ & 0.86 \\
Walking ability & $3.4 \pm 2.9$ & $2.5 \pm 2.5$ & 0.08 \\
Normal work & $3.3 \pm 2.9$ & $2.9 \pm 2.8$ & 0.45 \\
Relationships with other people & $3.6 \pm 3.1$ & $3 \pm 2.8$ & 0.28 \\
Enjoyment of life & $4.1 \pm 3.7$ & $3.4 \pm 2.7$ & 0.24 \\
\hline
\end{tabular}

\section{Discussion}

When the female patients with breast cancer and healthy women who participated in this study were compared, no difference was found between sociodemographic characteristics, regular medication use and smoking, except for education level. The vast majority of the 
patient group diagnosed with breast cancer (64.9\%) consisted of patients whose treatment was completed and in remission. In this study, no difference was found between the level of physical activity and fatigue in breast cancer patients compared to healthy individuals. It had been determined that women diagnosed with breast cancer had been more precontemplation and preparation stage of physical activity behaviours than healthy women.

The risk of breast cancer increases with age. Approximately $70 \%$ of women diagnosed with breast cancer were over the age of 50 (17). Ozmen et al, the study which they analysed 20.000 breast cancer patients in Turkey, they found the average age was 51 years (18). The average age of female patients diagnosed with breast cancer who participated in our study was calculated as 51.7 years, similar to the results of previous research.

In previous studies, higher education level was associated with a higher incidence of breast cancer (19). In a study examining the data of women aged 35 years and over in Norway between 1971 and 2009, the incidence of breast cancer was found to be higher in women with higher education compared to women with a lower education level before the millennium. Although there was a decrease in educational differences after the millennium, it was reported that during 2000-2009, the incidence of breast cancer was still higher for women with higher education compared to women with low education, at a rate of $38 \%$ (20). A recent meta-analysis concluded that women with university or higher education had a significantly increased risk of breast cancer compared to women with lower education levels, but the mechanisms by which higher education levels were associated with increased breast cancer risk remain unclear (21). In our study, when the education levels of the groups were examined, it was determined that the patients in the cancer group had a lower education level. This situation may be related to the region and hospitals where the study was conducted and the socioeconomic status of the sample group. Other factors, varying with the effect of education level, seem to pose difficulties in making inferences directly related to cancer risk.

In the study of Gal et al., in which women with breast cancer investigated their physical activity levels every 6 months and compared them with healthy women in the general population, they found that women diagnosed with breast cancer were less physically active than the general population for up to 3 years after diagnosis (22). Similarly, Philips et al., in their study investigating the physical activity and sedentary behaviour of breast cancer patients, showed that the breast cancer group was more sedentary and participated in less low-intensity activity than the control group; they stated that although they recorded more time in medium and high intensity activities compared to the control group, these levels were insufficient compared to the recommended levels for both groups (23). Unlike the studies mentioned, Shi et al. found that individuals diagnosed with breast cancer showed a higher level of physical activity compared to the healthy control group (24). In our study, as in the study of Kwon et al. (25), no difference was found in the level of physical activity in patients diagnosed with breast cancer compared to healthy individuals. It was thought that differences in factors such as health habits, 
lifestyles, education levels and policies that encourage physical activity may have an effect on this diversity of results (23). In our study, although it was pleasing that those diagnosed with cancer did not differ from their healthy counterparts, it is a situation that needs to be studied to increase their physical activity levels.

In the literature, there were studies that show a high variability between $14 \%$ and $96 \%$ in the fatigue prevalence of breast cancer patients (7). In a study by Canário et al., fatigue symptoms were detected at a rate of $72 \%$ (8). In this study, it was found that $35.1 \%$ of the patient group diagnosed with breast cancer felt tired. It had been concluded that this variability may arise from many factors such as daily life activities, mental state and treatment process.

Salmon et al., evaluated the 2-year followup data of 466 women newly diagnosed with invasive breast cancer in order to determine adaptation patterns in breast cancer patients with cancer-related fatigue. They found that there was an increase in fatigue at 8 months of follow-up, followed by a decrease between 8 and 24 months. They commented that the patients could respond differently to the questionnaires over time, not only because of the change in their fatigue, but also because of the change in their perception of what fatigue meant for them (26). In this study, it was observed that fatigue, its severity and its effect on daily life did not make a difference between the groups according to the BFI. This situation was thought to be due to the subjectivity of people's perception of fatigue and the fact that the cases in our study were mostly in remission and included in daily life with wellness.

On the other hand, it is known that chemotherapy treatment is a strong trigger for fatigue (7). Increasing physical activity is beneficial during chemotherapy treatment, but the symptoms associated with the treatment can sometimes be an obstacle to physical activity. In various studies, it had been reported that in people with breast cancer, especially during chemotherapy treatment, the patient's physical activity level decreased due to drug-related side effects, fatigue and emotional state and the time spent inactive increased by limiting their physical activity during the day $(27,28)$. In a review by Clifford et al., they stated that the most frequently reported obstacle in starting or continuing exercise in different cancer groups were side effects related to treatment, followed by lack of time and fatigue, and they also found that there was a lack of knowledge about exercise in cancer patients (29).

There were various studies concluded that physically active breast cancer patients had a lower percentage of fatigue symptoms compared to sedentary patients with breast cancer, they were more psychologically adapted to treatment, experience less fatigue symptoms and their functional capacity and quality of life were higher $(8,28,30)$. Also, Roger et al. in a study they performed on 222 breast cancer patients whose treatments were completed, they found that 3-month exercise intervention reduced anxiety and depression levels along with fatigue (31).

Felser et al. in a cross-sectional study using a 5-step transtheoretic model to define exercise motivation in patient groups with different cancer diagnoses, they found that patients who had no experience with exercise were more in the precontemplation phase, whether they were informed or not. It had been said that most 
of the patients who were physically inactive before the disease were in the contemplation stage, while the majority of the patients who were physically active before the disease were in the action and maintenance stage (32). Mowls et al. and Büntzel et al. similarly, it was reported in their studies that exercise experience before cancer disease and/or during cancer treatment increased exercise habits $(33,34)$. In the study of Rogers et al., a relationship was found between lower education level and indifference to exercise programs in patients with breast cancer living in rural areas (35). In our study, it was found that women diagnosed with breast cancer had a lower education level and they were more in the 'precontemplation' and 'preparation' stages of the stages of exercise change. In the light of all these data, it is necessary to provide adequate information to cancer patients about the importance/necessity of exercise in order to eliminate the lack of information, as well as practices that will ensure that they have sufficient motivation to do physical activity.

Following the World Health Organization's recommendations for leisure physical activity ( $\geq 10$ MET hours per week) is associated with a significantly lower risk of breast cancer (36). It is known that insufficient physical activity increases the risk of breast cancer and in patients diagnosed with breast cancer, physical activity decreases for various reasons. For this reason, it has an important potential to direct individuals to physical activity in order to prevent breast cancer in healthy individuals and to reduce the disease burden and improve survival outcomes in individuals diagnosed with breast cancer (37). Considering that many factors play a role in adapting to the exercise program, a holistic treatment approach should be adopted by including exercise programs specially designed for breast cancer patients into the cancer treatment process.

\section{Limitations of Study}

The cross-sectional features of the study, the determination of physical activity level based on the last one week's data and the use of qualitative assessment tools to evaluate the symptom such as fatigue based on subjective evaluation constituted our limitations. In addition, the fact that more than half of the patients diagnosed with breast cancer included in the study were in the remission process was another limitation.

\section{Conclusion}

Although a decrease in exercise capacity in patients diagnosed with cancer is an expected result, it is not an inevitable end. It should not be overlooked that fatigue symptoms in women diagnosed with breast cancer may appear through various mechanisms, various support and training services should be planned to encourage exercise.

\section{Conflict of Interest}

The authors declare no conflict of interests.

\section{Acknowledgment}

Authorship Contributions: Idea/Concept and design; SE, FB, CÇ, control/supervision; SE, FB, CÇ, MK, data collection and/or processing; $\mathrm{AO}, \mathrm{MK}$, analysis and/or interpretation; SE, literature review; $\mathrm{SE}, \mathrm{FB}, \mathrm{CC}, \mathrm{AO}, \mathrm{EA}$, writing the article; SE, EA, AO, critical reviewing; all authors. There are no funding sources.

We would like to thank Isparta Kansev Association employees, especially Cemaliye Bardakçı, Nurcan Anakurt and Halil Tanriverdi; Sakarya Cancer 
Association employees, especially Nihal Akar and Sibel Akar, who contributed to the preparation process of this study with their devoted work.

\section{References}

1. Siegel R, Naishadham D, Jemal A. Cancer statistics. CA Cancer J Clin. 2012;62(1):10-29.

2. Kozan R, Tokgöz Y. Türkiye'de Meme Kanseri Farkındalığı ve Tarama Programı. ACU Sağlık Bil Derg 2016(4):185-188.

3. https://hsgm.saglik.gov.tr/depo/birimler/kanserdb/istatistik/Trkiye_Kanser_statistikleri_2016.pdf (Erişim tarihi: 21.09.2020)

4. Sun YS, Zhao Z, Yang ZN, et al. Risk factors and preventions of breast cancer. Int J Biol Sci. 2017;13(11):1387-1397.

5. Ligibel JA, Basen-Engquist K, Bea JW. Weight Management and Physical Activity for Breast Cancer Prevention and Control. Am Soc Clin Oncol Educ Book. 2019;(39):22-33.

6. Lipsett A, Barrett S, Haruna F, et al. The impact of exercise during adjuvant radiotherapy for breast cancer on fatigue and quality of life: A systematic review and meta-analysis. Breast. 2017;32: 144-155.

7. Backman M, Wengström Y, Johansson B, et al. A randomized pilot study with daily walking during adjuvant chemotherapy for patients with breast and colorectal cancer The OptiTrain project View project Optitrain View project. Acta Oncol. 2014;53(4):510-520.

8. Canário ACG, Cabral PUL, Paiva LCD, et al. Physical activity, fatigue and quality of life in breast cancer patients. Rev Assoc Med Bras. 2016;62(1): 38-44.

9. Bilgin AU. Kanser ilişkili halsizlik ve fiziksel egzersiz. Genel Tip Derg. 2014;24(1):3844.

10. Saglam M, Arikan H, Savci S, et al. International physical activity questionnaire: Reliability and validity of the Turkish version. Percept Mot Skills. 2010; 111 (1): 278-84.

11. Laporte RE, Montoye HJ, Caspersen CJ. Assessment of physical activity in epidemiologic research: Problems and prospects. Public Health Rep. 1985;100: 131-46.

12. Cengiz C, Aşçı F. Egzersiz Davranışı Değişim Basamakları Anketi. Türkiye Klinikleri Spor Bilimleri Dergisi. 2010;2(1):32.
13. Usta Yeşilbalkan O, Karadakovan A. Kemoterapi uygulanan Hastalarda Eğitimin Yorgunluk Düzeyine ve Yaşam Kalitesine Olan Etkisinin İncelenmesi. ( $\mathrm{PhD}$ thesis). Ege Üniversitesi, 2015.

14. Gok ZM, Karadas C, Izgu N, et al. Effects of progressive muscle relaxation and mindfulness meditation on fatigue, coping styles, and quality of life in early breast cancer patients: An assessor blinded, three-arm, randomized controlled trial. Eur J Oncol Nurs. 2019; 42 :116-125.

15. Chang YJ, Lee JS, Lee CG, et al. Assessment of clinical relevant fatigue level in cancer. Support Care Cancer. 2007;15(7):891-896.

16. Erturk M, Yildirim Y, Kilic SP, et al. Pain and fatigue in elderly cancer patients: Turkey example. Holist Nurs Pract. 2015; 29(3): 167-173.

17. Çakır S, Kafadar MT, Arslan ŞN, et al. Meme kanseri tanısı konmuş kadınlarda risk faktörlerinin güncel veriler 1şı̆̆ında gözden geçirilmesi. FNG \& Bilim Tıp Dergisi. 2016; 2(3): 186-194.

18. Özmen V, Özmen T, Doğru V. Breast Cancer in Turkey; An Analysis of 20.000 Patients with Breast Cancer. Eur J Breast Health. 2019; 15(3): 141-146.

19. Hussain SK, Altieri A, Sundquist J, et al. Influence of education level on breast cancer risk and survival in Sweden between 1990 and 2004. Int J Cancer. 2008;122(1):165-169.

20. Trewin CB, Strand BH, Weedon-Fekjær $\mathrm{H}$, et al. Changing patterns of breast cancer incidence and mortality by education level over four decades in Norway, 1971-2009. Eur J Public Health. 2017;27(1): 160-166.

21. Dong J-Y, Qin L-Q. Education level and breast cancer incidence: a meta-analysis of cohort studies. Menopause. 2020;27(1):113-118.

22. Gal R, Monninkhof EM, Peeters PHM, et al. Physical activity levels of women with breast cancer during and after treatment, a comparison with the Dutch female population. Acta Oncol, 2019;58(5): 673-681.

23. Phillips SM, Dodd KW, Steeves J, et al. Physical activity and sedentary behavior in breast cancer survivors: new insight into activity patterns and potential intervention targets. Gynecol Oncol. 2015; 138(2):398-404.

24. Shi JW, MacInnis RJ, Boyle T, et al. Physical activity and sedentary behavior in breast and colon cancer survivors relative to adults without cancer. Mayo Clinic Proceedings. 2017; 92(3):391-398. 
25. Kwon S, Hou N, Wang M. Comparison of physical activity levels between cancer survivors and non-cancer participants in the 2009 BRFSS. J Cancer Surviv. 2012;6(1):54-62.

26. Salmon M, Blanchin M, Rotonda C, et al. Identifying patterns of adaptation in breast cancer patients with cancer-related fatigue using response shift analyses at subgroup level. Cancer Med. 2017;6(11):2562-2575.

27. Baumann FT, Bieck O, Oberste M, et al. Sustainable impact of an individualized exercise program on physical activity level and fatigue syndrome on breast cancer patients in two German rehabilitation centers. Support Care Cancer. 2017;25(4):1047-1054.

28. Phillips SM, Welch WA, Fanning J, et al. Daily Physical Activity and Symptom Reporting in Breast Cancer Patients Undergoing Chemotherapy: An Intensive Longitudinal Examination. Cancer Epidemiology and Prevention Biomarkers.2020. Doi: 10.1158/1055-9965.EPI-20-0659.

29. Clifford BK, Mizrahi D, Sandler CX, et al. Barriers and facilitators of exercise experienced by cancer survivors: a mixed methods systematic review. Support Care Cancer. 2018;26(3):685-700. 30. Stagl JM, Antoni MH, Lechner SC, et al. Postsurgical physical activity and fatigue-related daily interference in women with non-metastatic breast cancer. Psychol Health. 2014;29(2):177-198. 31. Rogers LQ, Courneya KS, Anton PM, et al. Effects of a multicomponent physical activity behavior change intervention on fatigue, anxiety, and depressive symptomatology in breast cancer survivors: randomized trial. Psychooncology. 2017; 26(11): 1901-1906.

32. Felser S, Behrens M, Lampe $\mathrm{H}$, et al. Motivation and preferences of cancer patients to perform physical training. Eur J Cancer Care (Engl). 2020;29(4):e13246.

33. Mowls DS, Brame LS, Martinez SA, et al. Lifestyle behaviors among US cancer survivors. J Cancer Surviv. 2016;10(4):692-698.

34. Büntzel J, Kusterer I, Rudolph Y, et al. Cancer Patients' Knowledge and Acceptance of Physical Activities for Rehabilitation. In Vivo. 2017;31(6):1187-1192.

35. Rogers LQ, Markwell SJ, Verhulst S, et al. Rural breast cancer survivors: Exercise preferences and their determinants. Psychooncology. 2009;18(4):412-421.

36. Liu L, Shi Y, Li T, et al. Leisure time physical activity and cancer risk: evaluation of the WHO's recommendation based on 126 high-quality epidemiological studies $\mathrm{Br} \quad \mathrm{J}$ Sports Med. 2016;50(6):372-378.

37. Jones LM, Reinhoudt LL, Hilverda F, et al. Using the Integrative Model of Behavioral Prediction to Understand Female Breast Cancer Survivors' Barriers and Facilitators for Adherence to a Community-Based Group-Exercise Program. Semin Oncol Nurs. 2020;36(5):151071. 